\title{
28 Resarach Square \\ Contents and Quality of Malaria Information in Spanish Travel Blogs
}

\section{Manuel Linares-Rufo}

Hospital Universitario Príncipe de Asturias: Hospital Universitario Principe de Asturias

\section{Laura Santos-Larrégola}

fundacionio

\section{Miguel Górgolas-Hernández-de-Mora}

Universidad Autónoma de Madrid: Universidad Autonoma de Madrid

José-Manuel Ramos-Rincon ( $\square$ jose.ramosr@umh.es)

Miguel Hernandez University of Elche Faculty of Medicine: Universidad Miguel Hernandez de Elche Facultad de Medicina https://orcid.org/0000-0002-6501-9867

\section{Research}

Keywords: Malaria, Traveler, Tourist, Blog, Social Networks, Traveler Advice, Chemoprophylaxis, Prevention

Posted Date: May 25th, 2021

DOl: https://doi.org/10.21203/rs.3.rs-551987/v1

License: (c) (1) This work is licensed under a Creative Commons Attribution 4.0 International License. Read Full License

Version of Record: A version of this preprint was published at Malaria Journal on August 16th, 2021. See the published version at https://doi.org/10.1186/s12936-021-03864-2. 


\section{Abstract}

Background. About 10,000 imported cases of malaria are reported each year in Europe; 80 per 100,000 trips to endemic areas. Non-use of chemoprophylaxis in travelers remains the main reason for this. Travel blogs have proliferated throughout the network being a very common place to consult, sometimes the only one used, before preparing a trip to an endemic area. The aim of this study was to analyze the information offered on malaria in the main travel blogs in Spanish.

Methods: we selected and analyzed 100 travel blogs that were considered highly relevant by its metrics: by 1) Social networks (RRSS) measuring the total followers of Facebook, Twitter, Instagram and YouTube), 2) number of monthly visits using the SEMrush tool; 3) Domain authority and 4) number of backlinks or incoming links considering the age and the percentage according to category using the SEMrush tool.

Results: To this end, the 100 Spanish-language travel blogs with the greatest impact were selected and analyzed. The results showed a very low quality of information provided by these publications. The contents offered were generally insufficient, incomplete or, more seriously, inadequate. In many cases, this could encourage the user not to take the appropriate preventive measures.

Conclusions: This study showed a low quality of travel blogs in Spanish regarding malaria. The so-called "travel influencers" must communicate reliable, verified and quality information on malaria on their channels in a way that could contribute to a reduction in the burden of the disease in our environment

\section{Introduction}

About 10,000 imported cases of malaria are reported in Europe each year; 80 for every 100,000 trips to endemic areas. The global incidence of the disease was estimated at 229,000,000 cases in 2019, of which more than $50 \%$ occurred in Africa [1]. Despite having two official databases; the real burden of imported malaria in Spain seems to be underestimated [2]. There is also a great limitation for calculating its prevalence as only surveys are available and not the actual number of travelers by origin and destination [3]. The figures of cases offered by the European Center for Disease Prevention and Control (ECDC) for Spain show a growing trend in recent years: 688 cases (year 2014), 706 (2015), 755 (2016), 818 (2017) and 851 (2018) [4]. Data most likely related to the increase in travelers to risk areas. In 2018, $9.8 \%$ of the 197.5 million trips made by Spaniards went abroad [3]

The risk of imported malaria is known to be higher in travelers from Africa, especially immigrants and visiting friends and relatives (VFRs). There are many studies that indicate that the non-use of chemoprophylaxis is still too common among imported malaria cases, particularly among these groups and others less expected such as young people or travelers with a high educational level $[5,6]$.

"Unofficial" information or consultation such as travel blogs on the attitude of the traveler. Travel blogs have proliferated across the entire web. Travelers learn from them or seek specific information for 
upcoming destinations. The objective of this work was to analyze the information offered on malaria in the main travel blogs in Spanish.

\section{Material And Methods}

To do this, we selected and analyzed 100 travel blogs that were considered highly relevant by its metrics (supplementary material). This selection was made based on the metrics obtained with the following external tools: 1) Social networks (RRSS) measuring the total followers of Facebook, Twitter, Instagram and YouTube), using Influencer "Marketing Hub", "Fanpage Karma" and "Metricool"; 2) number of monthly visits using the SEMrush tool; 3) Domain authority (DA), using the MOZ tool and 4) number of backlinks or incoming links considering the age and the percentage according to category using the SEMrush tool.

The blog's own search engine was used to find content that included the word "malaria", video and podcast formats were also included. For the evaluation of the quality of the information provided, the different posts found were answered with dichotomous answers to the questions shown in Table 1

\section{Results}

Of the 100 blogs analyzed, 36 of them (36\%) did not provide any type of information regarding malaria, even though they were pages that offered recommendations for visiting endemic countries. Paradoxically, $95 \%$ did offer advertising or advertising content about travel health insurance.

Of the 64 that did offer information, it should be noted that $75 \%$ had a line about malaria in the forum or comments to the post and $68.8 \%$ collected information on the adverse effects of chemoprophylaxis. Only one in three blogs was the information up to date (Table 1). 
Table 1

Quality items from traveler blogs

\begin{tabular}{|lll|}
\hline Quality items & $\mathrm{n} / \mathrm{N}$ & $\%$ \\
\hline Does the blog offer information on malaria? & $64 / 100$ & $64 \%$ \\
\hline Is there a discussion line on malaria in the forum or comments to the post? & $48 / 64$ & $75 \%$ \\
\hline Does the blog collect information on the side effects of chemoprophylaxis? & $44 / 64$ & $68.8 \%$ \\
\hline Is the information you provide up-to-date? & $22 / 64$ & $34.4 \%$ \\
\hline Does the blog offer links to official / specialized travel medicine websites? & $10 / 64$ & $15.6 \%$ \\
\hline $\begin{array}{l}\text { Does the blog advise non-certified preventive products against malaria or whose } \\
\text { effectiveness is in question? }\end{array}$ & $10 / 64$ & $15.6 \%$ \\
\hline $\begin{array}{l}\text { Does the blog have adequate information on chemoprophylaxis? } \\
\text { Is the information that the blog provides referenced? }\end{array}$ & $7 / 64$ & $10.9 \%$ \\
\hline $\begin{array}{l}\text { Does the blog provide correct information on SBET "standby emergency } \\
\text { treatment"? }\end{array}$ & $4 / 64$ & $6.3 \%$ \\
\hline $\begin{array}{l}\text { The information offered by the blog on malaria Has it been generated or reviewed } \\
\text { by a healthcare professional? }\end{array}$ & $2 / 64$ & $3.1 \%$ \\
\hline
\end{tabular}

Only $10(15.6 \%)$ provide links to official / specialized websites (International vaccination centers [ $\mathrm{n}=5]$, Ministry of Health [ $n=2]$, other specialized websites dedicated to travel medicine [ $n=3])$. Ten $(15.6 \%)$ of the blogs advised non-certified preventive products against malaria or whose effectiveness is in question, such as garlic, onion, vitamin B, bracelets, nitrous oxide, various cosmetics, anti-mosquito candles, electrical or ultrasonic devices such as repellants of mosquitoes. It was noted that only $10.93 \%$ had adequate information on chemoprophylaxis and $6.25 \%$ the information was referenced. Only $3.12 \%$ of the blogs provided correct information about self-treatment and the information was generated or reviewed by a healthcare staff (Table 1)

In the qualitative analysis of the blogs, the following important misconceptions were detected, which were relevant to the board:

- 12 of them recommended "the malaria vaccine" for travel. Clear confusion with the concept of chemoprophylaxis.

- The dosage of antimalarials in many cases was wrong or their indication was outdated (For example, they spoke of the use of chloroquine in areas of current resistance).

- Description of chemoprophylaxis side effects appears in 44 blogs. We highlight in some of them words such as: "poison, serious complications, aggressive pills or a psychotic break".

- Some of the blogs recommended products based on vitamin B or repellants and devices against mosquitoes of doubtful efficacy and scientifically unproven. 


\section{Discussion}

This study showed a low quality of travel blogs in Spanish regarding malaria. The contents offered were generally insufficient, incomplete or, what is more serious, inadequate. Being able to encourage in many cases the user not to take adequate preventive measures. Their scientific quality may be related to a greater number of imported malaria cases and severe cases of it. Since the traveler takes the advice of the information they offer without being well documented or endorsed by the opinion of experts in the field.

The efforts already begun in prevention against malaria in other groups such as travel agents or in very specific contexts of travelers are known [7]. However, in the field of travel blogs, these initiatives so far are practically nonexistent. More in the current context of infoxication or the presence of fake news presented by the networks [8].

Sometimes travelers' perceptions of malaria risks are unrealistic. Thus, travel blogs should be realistic and correct misperceptions (such as believing that curing malaria is easier than taking prophylaxis or that travelers visiting relatives have some level of innate immunity). It could establish "filter criteria" in travel blogs and let the user be the one to evaluate the information obtained. As in other sources of information, currently called "classic", such as newspapers, radio or television, where the messages and their content may be erroneous, incomplete or present a totally biased point of view, and they are not for that reason ceased. use, being the user who forms his personal judgment.

Possibly, the existence of codes of conduct and ethics, such as HONcode [9], could be a more reliable way of the existence of quality and credible information, since a significant proportion of people have low health literacy, and these have difficulties accessing this information, assessing its quality, and applying it to their own circumstances [10]. The so-called "travel influencers" must communicate reliable, verified and quality information on malaria on their channels in a way that could contribute to a reduction in the burden of the disease in our environment.

Our results should be interpreted in light of the study's limitations. First of all, the study was performed in Spanish blogs, and can be different than English blogs. And Second, the criteria of measurement of quality is based in subjective experience of research.

In conclusion, travel blogs in Spanish regarding malaria has a low quality, the contents offered were generally insufficient, incomplete or, what is more serious, inadequate. Further studies are necessary to know the real low quality, the contents about malaria in travel blogs

\section{Declarations}

\section{Ethics approval and consent to participate}

According to the Spanish law, approval by an ethics committee was not necessary for this study. 


\section{Consent for publication}

Not applicable

\section{Availability of data and materials}

J.M.R.R. has full access to and is the guarantor for the data. The datasets generated are available from the corresponding author on reasonable request.

\section{Competing interests}

The authors declare that they have no conflict of interest.

\section{Funding}

The authors received no specific funding for this work.

\section{Authors' contributions}

M.L.R., and L.S.L. collected the data, analysed the data and wrote the manuscript; M.G.H., and J.M.R.R. analyzed the data and revised and edited the manuscript. All authors read and approved the final manuscript.

\section{Acknowledgements}

We many thank the contributions and ideas of all the travel bloggers consulted.

\section{Funding}

The authors received no specific funding for this work.

\section{Conflict of interest}

The authors declare that they have no conflict of interest.

\section{Ethical approval}

Not required.

\section{Author contributions}

M.L.R., and L.S.L. collected the data, analysed the data and wrote the manuscript; M.G.H., and J.M.R.R. analyzed the data and revised and edited the manuscript. All authors read and approved the final manuscript.

\section{References}


1. WHO. World malaria report 2020. Geneva: World Health Organization; 2020. https://www.who.int/publications/i/item/9789240015791. Access 1 Feb 2021.

2. Herrador Z, Fernández-Martinez B, Quesada-Cubo V, et al. Imported cases of malaria in Spain: observational study using nationally reported statistics and surveillance data, 2002-2015. Malar J. 2019;18:230.

3. Instituto nacional de Estadística. INE. Available: https://www.ine.es/ Access 1 Feb 2021.

4. European Centre for Disease Prevention and Control. Introduction to the Annual Epidemiological Report [internet]. Stockholm: ECDC; 2020. Available: https://www.ecdc.europa.eu/en/publicationsdata/malaria-annual-epidemiological-report-2018 Access 1 Feb 2021.

5. Hoefnagel JGM, Massar K, Hautvast JLA. Non-adherence to malaria prophylaxis: The influence of travel-related and psychosocial factors. J Infect Public Health. 2020;13:532-7.

6. Ahluwalia J, Brooks SK, Weinman J, Rubin GJ. A systematic review of factors affecting adherence to malaria chemoprophylaxis amongst travelers from non-endemic countries. Malar J. 2020;19:16.

7. Bazaz R, Green E, Green ST. Quality of malaria information provided on Internet travel operator websites. Travel Med Infect Dis. 2010;8:285-91.

8. Domenico GD, Sit J, Ishizaka A, Nunan D. Fake news, social media and marketing: A systematic review. J Bus Res. 2021;124:329-41.

9. Health On the Net Foundation (HON Foundation). The HON Code of Conduct for medical and health Web sites (HONcode) [monograph on the Internet]. Geneva, Switzerland: HON Foundation; 2017 Disponible en: http://bit.ly/2PpHUcj Acceso 1 Feb 2021.

10. Charow R, Snow M, Fathima S, et al. Evaluation of the scope, quality, and health literacy demand of Internet-based anal cancer information. J Med Libr Assoc. 2019;107:527-37.

\section{Supplementary Files}

This is a list of supplementary files associated with this preprint. Click to download.

- SupplementarymaterialF.docx 